\title{
Prevalence of anemia among school going children $(<12$ years of age) in selected slum schools of Bhubaneswar, Odisha.
}

\author{
${ }^{1}$ Sujata Mohapatra, ${ }^{2}$ Soma Maity, ${ }^{3}$ Binati Behera, ${ }^{4}$ Sailabala Mohanty \\ BSN, RN, RM ${ }^{1,2,3}, \mathrm{MSN}, \mathrm{BSN}, \mathrm{RN}, \mathrm{RM}^{4}$ \\ Msc Nursing $2^{\text {nd }}$ Year (Community Health Nursing) ${ }^{1,2,3}$ \\ Lecturer, Department of Community Health Nursing ${ }^{4}$, SUM Nursing College, SOA University
}

\begin{abstract}
The purpose of the study is to assess the prevalence of Anemia among school going children of selected slum schools of Bhubaneswar, Odisha. Anemia is a common problem throughout the world and iron deficiency is the most prevalent nutritional deficiency in the world. It affects mainly the poorest segment of the population. An exclusive review of literature helped in preparation of data collection tools to assess the level of hemoglobin among school children.This study was conducted at the selected schools of slum area in Bhubaneswar. Sample size was 385. Study subjects were school children $(<12$ years).The design of the study was Non-Experimental Descriptive Design /Survey approach which was carried out in a group of 385 students selected by Non-Probability Convenience Sampling technique from selected slum schools of Bhubaneswar.A structured Questionnare was administerd to collect demographic data \& data on level of hemoglobin was collected by Sahli's method at Urban Health Training Centre, IMS \& SUM Hospital laboratory.The students \& school authority were assured for their confidentiality of their response.The analysis of the obtained data was based on the objective of the study. Descriptive \& inferential statistics was used for data analysis \& data interpretation. Results of the study revealed that $55 \%$ of the sample are male \& $45 \%$ of the sample are female, $42 \%$ of the sample are Christian, 53\% of the sample are Hindu \& 5\% of the sample are Muslim, $22 \%$ of the sample are in the group of 0-6 years, 32\% of sample are in the group of 6-8 years \& $46 \%$ of sample are 8-12 years, educational qualification of mother, $15 \%$ of the sample were in the group of illiterate, $35 \%$ of sample were in the group of primary, $40 \%$ of sample are in the secondary group \& $10 \%$ sample are in the higher secondary group, $36 \%$ of the sample were in the group of business, 34\% of sample are in the group of service, $04 \%$ of sample are in the farmer group \& 26\% sample are in the Labourer group, 59\% of the sample were in the group of nuclear family, $41 \%$ of sample were in the group of joint family, $32 \%$ of the sample are not anemic \& $58 \%$ of sample are anemic. After analysis \& interpretation of data a leaflet regarding how to improve hemoglobin level through supplimenting balance diet was developed \& communicated to the parents \& school authority as more number of students are staying in school hostel.
\end{abstract}

Key words: Anemia, School going children, Nutritional anemia, Iron deficiency anemia, Slum school, Balance diet.

\section{Introduction}

Blood sustains life. It delivers oxygen, nutrients and other essential substances, including vitamins and medicines to the different cells and tissues of the body. A deficiency in the supply or quality of blood will impair the quality of life and even compromise life itself. Anemia is a condition in which blood does not have enough hemoglobin or red blood cells. Anemia has many causes. One of the most common is an inadequate intake of iron in the diet. Iron Deficiency Anemia is a condition where a person has inadequate amounts of iron in the blood to meet body demands. Iron Deficiency Anemia is the most common cause of nutritional anemia in the world. Children in the 6 to 24-months of age are at high risk, but the entire preschool age period may be vulnerable, especially in developing countries. According to a recent region and country survey, Iron Deficiency Anemia is widespread among children $<5$ years of age.

Anaemia is one of the most common nutritional problems in many parts of the world, especially in developing countries. A major health consequence of anaemia includes impaired cognitive and physical development in children. Low intake of iron-rich food is a risk factor for stunting. Other consequences include reduced work capacity in adults as well as increased risk of maternal and child mortality and morbidity and poor pregnancy outcome.

Anaemia was defined according to World Health Organization (WHO) cut-offs as $\mathrm{Hb}$ level $<12.0 \mathrm{~g} / \mathrm{dL}$ for girls and $<12.0 \mathrm{~g} / \mathrm{dL}$ for boys under 15 years old or $13 \mathrm{~g} / \mathrm{dL}$ for boys aged 15 years and over . Mild anaemia was defined as $\mathrm{Hb}$ levels between $9.0 \mathrm{~g} / \mathrm{dL}$ and the cut-off points, moderate anaemia was $\mathrm{Hb} 7.0-8.9 \mathrm{~g} / \mathrm{dL}$ and severe anaemia was $\mathrm{Hb}<7.0 \mathrm{~g} / \mathrm{dL}$. 
Numerous studies among children have shown that the prevalence of anemia ranges from 52-96.50\% in India. Iron Folic Acid supplementation remains the main strategy for combating anemia and improving hemoglobin status of adolescent girls and nutritional suppliments is a complementary strategy to improve it.

Diet is the most important way to prevent and treat iron deficiency. Foods containing abundant vitamin-C should also be provided for children, which can improve the absorption of iron. The collocation of suitable foods also plays an important role in accelerating the absorption of iron for children.

\section{I.1 Statement of the Problem}

Prevalence of anemia among school going children (below 12 years of age) in selected slum schools of Bhubaneswar, Odisha.

I.2. Aim of the study This study aimed to evaluate anemia by assessing haemoglobin level of some slum school going children \& parental attitude towards anemia prevention \& treatment.

\section{I.3. Objectives of the study:}

1. Determine the prevalence of Anemia among school going children (below 12 years of age).

2. Identify the Hemoglobin level of school children in selected slum school of Bhubaneswar, Odisha.

3. Recognize association between demographic variables with \& within prevelance of anemia among school going chiildren.

\section{1. Research Methodology}

\section{Materials \& Methods}

\section{Research Approach: Quantitative Research Approach}

Research Design: A cross-sectional survey design was used in this study.

Setting: This study was conducted at the selected slum schools of Bhubaneswar, Odisha.

\section{II.2. Sample Population:}

Sample Size: Sample size was calculated by Cochrane formula \& was found to be 385 .

Sampling Techniques: Non-Probability convenience sampling

Samples: A total of 385 students below 12 years of age, who satisfy the inclusion criteria are selected for the study.

Inclusion criteria are-

a) The school children those who are studying in selected slum schools of Bhubaneswar, b) Those who are willing to participate in this study. c) Those who will be available during study.

Exclusion criteria are-

a) The students those who are more than 12 years old. b) Those who are not willing to participate in this study.

c) Those who are absent on the data collection day.

\section{II.3 Research tool for data collection:}

Self structured questionnaire was developed to assess the prevalence of anemia was based on-related review of literature received from books,journals,published \& unpublished research studies, Consultant \& guidance from various subjects,experts \& in related fields were taken, Past experience of the investigator, Formal \& non-formal discussion with peer groups \& Consultation with statistician for data analysis. After revealing the research \& non-research material,opinion from experts, a self structured questionnaire was constructed for collecting socio-demographic data \& to assess the prevalence of anemia. The tool used in the presnt study includes the following section. Section- A include socio-demographic data \& Section- B include primary information on Anemia.

II.4.Pilot study: Pilot study was carried out on $10 \%$ of total sample and it was excluded from the study subject to test the feasibility, applicability and the clarity of the questionnaire and to estimate the length of time needed to fill the sheet. As a result of the pilot study, the necessary modification in the tools was done and the final form was developed.

II.5. Implementation phase: Data collection period for this study was from February 2013 to August 2013, the researchers collect the data during the morning from 9A.M. to 11A.M, three days/week, at the selected schools located in slum area of port-said city. The researcher filled the questionnaires by interview method.The researcher were read items of the questionnaire to them within 10-15 minutes wherein the aim of the study were explained to them to obtain their cooperation for data collection. 
Prevalence of anemia among school going children ( $<12$ years of age) in selected slum schools .....

II.6. Ethical consideration At the initial interview, all subjects were informed about the nature, purpose and benefits of the study and that their participations were voluntary. They were individually interviewed to evaluate cigarette smoking and nicotine dependence among physicians, employees and their attitudes towards smoking free workplace in port-said city. Also, all the information like school name \& student's name was kept confidentially.

II.8. Limitation of the study: The scope of the study was limited as it was restricted to 6-12 years age group, those are willing to participate $\&$ those are available during study period.

II.9. Validity and reliability: Validity: questionnaire sheet was revised by nursing experts. Cronbach's coefficient Alpha reliability it is equal (0.84).

Data Analysis:

\section{Figures \& Tables}

Statistical analysis involves segmentation of a complex problem to smaller section \& the smaller segment are analyzed, then the result co-relted with respect to the whole process in order to solve the problem. The data analysis was carried out by using both descriptive, inferential statistics and on the basis of objectives of the study \& the hypothesis set by the investigator.

Table-1: Distribution of the sample according to hemoglobin level

\begin{tabular}{|l|l|l|}
\hline HEMOGLOBIN LEVEL & FREQUENCY & PERCENTAGE \\
\hline NO ANEMIA & 82 & $21 \%$ \\
\hline ANEMIA & 303 & $79 \%$ \\
\hline
\end{tabular}

Table-1 Shows the distribution of the subjects according to the level of hemoglobin, depicts that $21 \%$ of the sample were not anemic \& $79 \%$ of sample were anemic $(<8 \mathrm{mg} / \mathrm{dl})$.

Figure-1: frequency distribution of the sample according to hemoglobin level

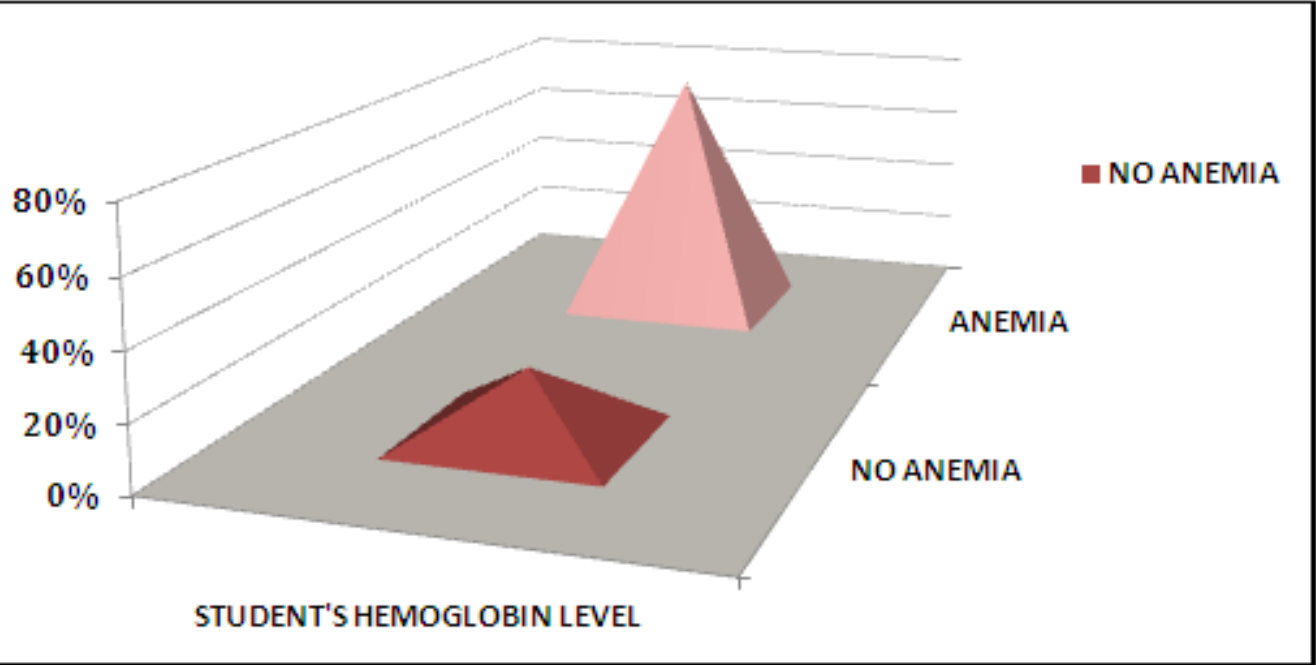

Figure-1 display that $21 \%$ of students were not anemic \& $79 \%$ of students were anemic.

Table-2: Frequency distribution of the sample according to gender

\begin{tabular}{|l|c|c|}
\hline \multicolumn{1}{|c|}{ GENDER } & FREQUENCY(f) & PERCENTAGE(\%) \\
\hline MALE & 238 & $62 \%$ \\
\hline FEMALE & 147 & $38 \%$ \\
\hline
\end{tabular}

Table -2 , illustrates that distribution of the subjects according to gender depicts $62 \%$ of the sample were male \& $38 \%$ of the sample were female. 
Figure-2: Frequency distribution of the sample according to gender

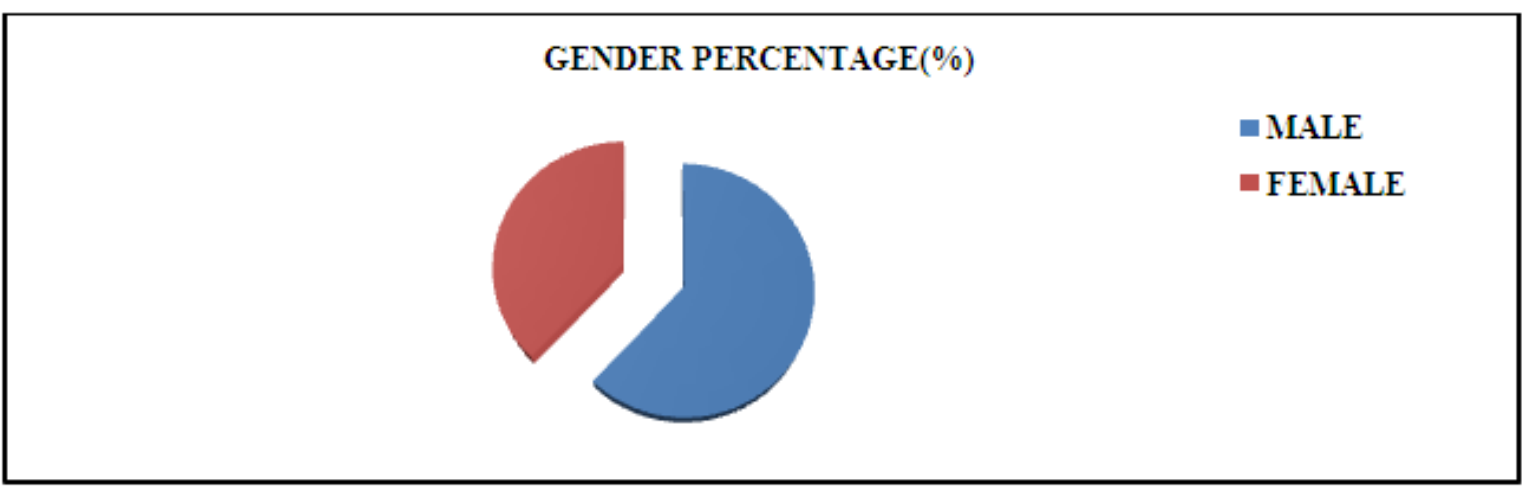

Figure -2, displays that distribution of the subjects according to gender depicts $62 \%$ of the sample were male \& $38 \%$ of the sample were female.

Table-3: Association between Anemia \& demographic variables

\begin{tabular}{|l|c|c|c|c|}
\hline Demographic Variables & df & Calculated $\chi^{2}$ value & Table $\chi^{2}$ Value & Remark \\
\hline Religion educational & 2 & 1.6 & 5.99 & Not significant at 0.05 \\
\hline $\begin{array}{l}\text { Mother's } \\
\text { qualification }\end{array}$ & 2 & 18.7 & 5.99 & Significant at 0.05 \\
\hline Family Income dietary & 1 & 6.21 & 5.99 & Significant at 0.05 \\
\hline $\begin{array}{l}\text { Parental } \\
\text { awareness }\end{array}$ & $\mathbf{3 0 . 0 8}$ & $\mathbf{3 . 8 4}$ & Highly significant at 0.05 \\
\hline
\end{tabular}

Table-3 depicts that religion of students was not significantly associated with prevalence of Anemia at 0.05 level of significance, where as mother's educational qualification, family income \& parental dietary awareness were significantly associated with prevalence of Anemia among sample at 0.05 level of significance.

\section{Discussion}

This study was conducted to assess the prevalence of anemia among school children upto 12 years of age \& the result found was $79 \%$ of students are anemic. This study findings shows that $62 \%$ of the sample are male \& $38 \%$ of the sample are female.The statistical analysis for association results highly significant association betwee parental dietary awareness with anemia prevalence, sigificant association between educational qualification of mother, family income with Anemia prevalence \& no such significant association of religion with anemia prevalence.

\section{Recommendation}

Keeping view the finding this study report, the following recommandations are made;

1. Health awareness programme for the community nurses should be conducted, so that they can develop their content awareness and clear understanding about the level of hemoglobin and the causes of deficiency hemoglobin among the school children.

2. Government should impliment school health programme in conducting hemoglobin estimation for all school children in a regular basis.

3. School teachers should give advice to both children \& parents regarding advantages of balance diet.

\section{Conclusion}

Nurses need to be aware of prevalence of Anemia among the school going children. Interventions should be implemented to increase the hemoglobin level in children. Nurses can educate parents, teachers and students regarding advantages of balance diet supplimentation and intake of iron rich food. This study contributes to the literature on prevalence of Anemia among school childrens of slum area. This study should be replicated inmore settings to see if the findings are similar. 


\section{Acknowledgement}

The authors are grateful to Almighty God for accomplishment of this research work. The authors are also wish to thank all the students, school staffs \& employees of UHTC, IMS \& Sum Hospital for their participation in this study.

\section{References}

[1]. Brown RG. Anemia. In: Taylor RB, ed. Family medicine: principles and practice. 4th ed. New York: Springer-Verlag, 1994:9971005

[2]. Little DR. Diagnosis and management of anemia. Prim Care Rep. 1997;3:175-84.

[3]. Centers for Disease Control and Prevention. Guidelines for school health programs to promote lifelong healthy eating. MMWR Morb Mortal Wkly Rep. 1996;45(RR-9):1-41.

[4]. Swain RA, Kaplan B, Montgomery E. Iron deficiency anemia: when is parenteral therapy warranted? Postgrad Med. 1996;100:18193.

[5]. Ghai ,O.P.,Gupta piyush, Paul V.k.Ghai’Esential pediatric;Published by O.P.Ghai,2004.

[6]. Gross R, Schultink W, Juliawati. Treatment of anemia with weekly iron supplementation [Letter]. Lancet. 1994;344:821.

[7]. Schultink W, Gross R, Gliwitzki M, Karyadi D, Matulessi P. Effect of daily vs twice weekly iron supplementation in Indonesian preschool children with low iron status. Am J Clin Nutr. 1995;61:111-5.

[8]. Swain RA, St. Clair L. The role of folic acid in deficiency states and prevention of disease. J Fam Pract. 1997;44:138-44.

[9]. Dickinson CJ. Does folic acid harm people with vitamin B ${ }_{12}$ deficiency? QJM. 1995;88:357-64.

[10]. Glass J. Iron deficiency anemia. In: Rakel RE, ed. Conn's Current therapy. 49th ed. Philadelphia: Saunders, 1997:349-52.

[11]. Angeles IT, Gross R, Schultink W, Sastroamidjojo S. Is there a long-term effect of iron supplementation on anemia alleviation [Letter]? Am J Clin Nutr. 1995;62:440-41. 